\title{
Online Sexual Activities in Italian Older Adults: The Role of Gender, Sexual Orientation, and Permissiveness
}

\author{
Cristiano Scandurra ${ }^{1}$ (D) . Fabrizio Mezza ${ }^{2} \cdot$ Concetta Esposito $^{2} \cdot$ Roberto Vitelli $^{1}$. Nelson Mauro Maldonato ${ }^{1}$. \\ Vincenzo Bochicchio ${ }^{3} \cdot$ Alessandro Chiodi $^{4} \cdot$ Alain Giami $^{5} \cdot$ Paolo Valerio $^{2} \cdot$ Anna Lisa Amodeo $^{6}$
}

Accepted: 18 January 2021 / Published online: 28 January 2021

(c) The Author(s) 2021

\begin{abstract}
Introduction Online sexual activities (OSAs) are sexual behaviors involving online sexual content and stimuli and are categorized into non-arousal (N-OSAs), solitary arousal (S-OSAs), and partnered arousal activities (P-OSAs). As such activities in older age remain largely underexamined, this study aimed to explore OSAs in a sample of Italian older adults, analyzing their associations with gender and sexual orientation, considering sexual permissiveness as a moderator.

Methods One hundred and fourteen cisgender participants ( 85 men and 29 women) aged from 52 to 79 years old $(M=62.57$, $S D=6.19)$ were recruited between September 2019 and January 2020 to participate in an online cross-sectional survey on OSAs.

Results A total of $58.1 \%$ of participants had engaged in S-OSAs at least 2-3 times during the previous month, while a lower percentage of participants had engaged in N-OSAs (38.6\%) and P-OSAs (29.9\%) at least 2-3 times during the previous month. Men were more likely to be engaged in S-OSAs than women. Being non-heterosexual was associated with an increase in engagement in N-OSAs and S-OSAs, but not in P-OSAs. Sexual permissiveness was significantly associated with N-OSAs and S-OSAs, but not with P-OSAs, and did not moderate either the relationship of gender with OSAs or that of sexual orientation with OSAs.

Conclusions This study sheds light on the need to include online resources in sexual health educational programs addressed at older people, as well as in training programs addressed at healthcare professionals and social workers working with this population.
\end{abstract}

Keywords Online $\cdot$ Sexuality $\cdot$ Aging $\cdot$ Gender $\cdot$ Sexual orientation $\cdot$ Sexual permissiveness

Cristiano Scandurra

cristiano.scandurra@unina.it

Fabrizio Mezza

fabrizio.mezza92@gmail.com

Concetta Esposito

concetta.esposito3@unina.it

Roberto Vitelli

rvitelli@unina.it

Nelson Mauro Maldonato nelsonmauro.maldonato@unina.it

Vincenzo Bochicchio

vincenzo.bochicchio@unical.it

Alessandro Chiodi

alessandro.chiodi@unina.it

Alain Giami

alain.giami@inserm.fr

Paolo Valerio

valerio@unina.it
Anna Lisa Amodeo

amodeo@unina.it

1 Department of Neuroscience, Reproductive Sciences and Dentistry, University of Naples Federico II, Via Sergio Pansini 5, 80131 Napoli, Italy

2 SInAPSi Center, University of Naples Federico II, Via Giulio Cesare Cortese 29, 80133 Napoli, Italy

3 Department of Humanistic Studies, University of Calabria, Via Ponte Bucci Cubo 18/C, 87036 Rende, Italy

4 Intradepartmental Program of Clinical Psychology, University Hospital of Naples Federico II, Via Sergio Pansini 5, 80131 Napoli, Italy

5 Center for Research in Epidemiology and Population Health, F-94807 Villejuif Cedex, France

6 Department of Humanistic Studies, University of Naples Federico II, Via Porta di Massa 1, 80133 Napoli, Italy 
In the last few decades, a growing body of research has highlighted the importance of sexuality in older age, debunking the general prejudicial perception of an 'asexual' age (Lindau et al., 2007; Træen et al., 2016; Skałacka \& Gerymski, 2018). Moreover, recent studies have indicated more positive attitudes towards sexuality in later life among diverse age cohorts (Bouman et al., 2006; Syme \& Cohn, 2015). At the same time, new generations of older adults have become increasingly more liberal than previous generations in their own attitudes towards sex and sexual behaviors, placing a higher value on their sexual health and pleasure (Schmidt \& Matthiesen, 2003; Syme, 2014; Træen \& Villar, 2020).

Since the beginning of the new millennium, which has been marked by a huge growth in Internet use and an increase in the number of older surfers (Mazur et al., 2012), the advantages that Internet may bring for sexual life have been recognized by all generations, including older adults (Adams et al., 2003). These benefits have been summarized by Cooper (1998) as the "Triple-A engine:" accessibility, affordability, and anonymity.

However, online sexual activities (OSAs) in older age, which are the focus of the current study, although having recently received more attention (e.g., Döring \& Mohseni, 2019; Ševčíková et al., 2020; Træen et al., 2018), remain largely underexamined, perhaps due to persistent stereotypes about older individuals as sexually inactive (Gewirtz-Meydan et al., 2018) and technologically incompetent (Mannheim et al., 2019). These ageist stereotypes may result in significant barriers to the enjoyment of sexuality and new technologies in later life, as they negatively shape the general perception of older adults, leading to social exclusion and invisibility.

The existing body of research on OSAs, primarily focused on adolescence and early adulthood, have highlighted that their prevalence and frequency differ as a function of sociodemographic characteristics, such as gender, sexual orientation, relationship status, and educational level, with men, non-heterosexual, single, and highly educated people generally reporting greater OSA use (Ballester-Arnal et al., 2017; Döring, 2009; Döring et al., 2015; Giordano \& Cashwell, 2017). Another fundamental variable related to OSAs is sexual permissiveness, which refers to the belief that expressions of sexuality should be open, free, and unrestrained, leading to liberal and tolerant attitudes toward various sexual behaviors such as premarital sex, teenage sex, extramarital sex, and same-sex sexual relationships (Martyniuk \& Štulhofer, 2018).

Since in Italy, which is the context of our study, research about OSAs in older individuals is scarce, the current work has been aimed at exploring OSAs in a sample of Italian older adults, as well as the relationships of OSAs with gender, sexual orientation, and sexual permissiveness. In the following paragraphs, we will first provide an overview of studies analyzing OSAs in older adults, as well as their links with gender and sexual orientation. We will then address the relationship between OSAs and sexual permissiveness. Finally, since our study has concentrated on Italy, we will provide a brief overview of Italian studies on sexuality in older adults.

\section{Online Sexual Activities in Later Life: Prevalence and Frequency}

OSAs refer to Internet-based activities and behaviors of a sexual nature. In line with Shaughnessy et al. (2011), OSAs may be categorized into (a) solitary-arousal activities (S-OSAs) (e.g., watching pornography without any other person present); (b) partnered arousal activities (P-OSAs) (e.g., engaging in webcam sex or sexual chat, activities which require a virtual interactive participation of at least two people); and (c) non-arousal activities (N-OSAs) (e.g., visiting sexual educational websites or chatting on dating websites).

As regards S-OSA, pornography viewing is the most widespread OSA for men of all ages (Cooper et al., 2003). For instance, statistics from the Canadian website Porn$h u b$, which is one of the most popular pornography platforms, showed that in 2016, the age group of 55 years or older constituted $11 \%$ of visitors $(7 \%$ aged between 55 and 64 years and $4 \%$ aged 65 years or over) (Træen et al., 2018). A recent European cross-cultural study investigating the prevalence of using the Internet for romantic or sexual purposes among people aged 60 to 75 years in Norway, Denmark, Belgium, and Portugal (Træen et al., 2018) found that watching pornography on the Internet decreased with increasing age in men, reflecting the decline in sexual interest and activity (Træen et al., 2016) and the lower Internet use in older age groups (Schreurs et al., 2017). Watching online pornography was more likely to be reported by men and women who masturbated and who were more satisfied with their current level of sexual activity. Furthermore, Træen et al. (2018) observed how this tendency is in line with studies showing that the general use of pornography is more common among highly sexually active individuals (Haavio-Mannila \& Kontula, 2003; Lewin et al., 2000), because they have a higher sex drive or place a higher value on their sex life.

As regards P-OSA, a significant research area concerns sexting, which is the transmission of sexually explicit messages, images, or photos via mobile phones or other electronic media (Klettke et al., 2014; Morelli et al., 2020). The prevalence of sexting in older adults is largely unknown (Klettke et al., 2014). Wysocki and Childers (2011) found that the incidence of sending nude photos decreased significantly, and in a linear manner, across increasingly older age groups from 19 to 24 years to $50+$ years of age. Similarly, 
findings from a US sample of single men and women ranging in age from 21 to $75+$ years suggested a decrease in the rates of sending and receiving sexually explicit material throughout the course of adult life (Garcia et al., 2016). In addition to age-related reductions in sexual behavior and deficits in technological literacy, this decline may be related to a greater perceived risk, since older men and women were more likely than younger people to believe that sexting could be harmful (Garcia et al., 2016). However, an Australian study (Malta, 2007) analyzing online romantic relationships among older adults (61-85 years) found that cybersex, which refers to the engagement of two or more people in online sexual talk for the purposes of sexual pleasure (Daneback et al., 2005), was or had been an integral part of many participants' relationships.

Regarding N-OSA, a larger number of studies exist relating to the search for a sexual or romantic partner. First, Alterovitz and Mendelsohn (2013) argued that the search for a sexual or romantic partner by older adults represents a means to decrease social isolation in later life. Similarly, in a literature review on this topic, Wion and Loeb (2015) concluded that online dating has become increasingly popular among older adults of different ages, who use such websites as a means to gain access to a wider community, to find serious relationships, to engage in casual dating, intimacy, and sexual relations, and to screen potential dates before meeting in person. At the same time, the ready accessibility of online dating may involve risks for older adults, who represent in this context potential victims of financial scams, personal data compromise, intimate partner violence, and emotional and sexual abuse (Vandeweerd et al., 2016; Wion and Loeb, 2015). According to Træen et al. (2018), the use of the Internet to find a committed partner decreases with increasing age in men, while relationship status and educational level were found to predict the use of the Internet to find a committed partner in both men and women, with non-partnered older adults and those with a lower education level reporting a higher incidence of browsing dating websites.

Within N-OSA, some studies have examined the use of the Internet as a source of education and information about sexuality in later life (Adams et al., 2003; Fileborn et al., 2016; Minichiello et al., 2013; Træen \& Daneback, 2012; Træen et al., 2018). Findings from a qualitative study with older Australian men and women aged 60 and over showed that the Internet was the most common source used by participants to learn about sex in later life, it being preferred to other means, such as the media, health care providers, books, workshops, or discussion groups (Fileborn et al., 2016). The Internet was indicated as a key source for a wide range of information on topics such as sexually transmitted infections, safer sex, sexual dysfunctions related to aging, sexuality, and sexual pleasure (Fileborn et al., 2016). Træen and Daneback (2012) found that, among Norwegian heterosexual people aged 18-67 years, seeking advice and information about sexual matters on the Internet was more common for women than for men. Furthermore, Træen et al. (2018) found a significant association in women between seeking sexual information and advice on the Internet and satisfaction related to the current level of sexual activity.

Finally, a recent work by Ševcíková et al. (2020) focused on problematic patterns of Internet use for sexual purposes in adults aged 50 and over, exploring the association between online sex addiction and specific vulnerabilities related to older age, such as changes in work career, boredom, and the absence of a partner. The study revealed that the risk of online sex addiction increased in line with lack of occupation due to unemployment or retirement and boredom, whereas the absence of a partner had no impact on the addiction development. Among OSAs, involvement in unpaid cybersex (i.e., sexual interaction mediated via online chat or webcams) was found to predict online sex addiction.

\section{Relationships of Online Sexual Activities in Older Adults with Gender and Sexual Orientation}

As can be seen from the previous paragraph, most studies on OSAs have been focused on gender differences, revealing that men generally represent the majority of users (Cooper, 1998; Shaughnessy et al., 2011). This trend has been confirmed for older people, with men being more involved in the use of the Internet for sexual purposes than older women, especially in relation to using online pornography (e.g., Döring et al., 2015; Döring \& Mohseni, 2019; Træen et al., 2018). This pattern confirms the difference between men and women in sexual behaviors, which persists into older adulthood (Baumeister et al., 2001; Lindau \& Gavrilova, 2010). This gender gap throughout the course of life may be explained in terms of the effect of gender socialization and is consistent with the traditional sexual stereotype which maintains that men have stronger sexual needs and motivations than women (Petersen \& Hyde, 2010; Wiederman, 2005).

Notwithstanding this, other studies (Bélanger Lejars et al., 2020; Döring et al., 2015) have revealed fewer differences in the frequency with which men and women engage in online sexual behaviors. For example, Daneback et al. (2005) found that women of 50-65 years engaged in cybersex more frequently than their male counterparts ( $22 \%$ vs. $13 \%)$. These findings suggest a progressive weakening of traditional gender norms in relation to sexuality and its expressions.

As regards sexual orientation, previous studies have generally found a greater prevalence and frequency of OSAs among non-heterosexual people (Ballester-Arnal et al., 2017; Döring, 2009; Giordano \& Cashwell, 2017). The Internet provides people belonging to stigmatized and marginalized minority identities, such as lesbian, gay, bisexual, and 
transgender (LGBT) people, an anonymous, easy, and relatively safe context to find possible partners and to express one's sexual preferences without fear of social stigmatization, especially in more restrictive and prejudiced environments (Daneback et al., 2005). Stigma and discrimination were pervasive in the historical context where LGB older adults have lived their youth, and this is particularly true in more restrictive and prejudiced environment (D'Augelli et al., 2001; Hässler et al., 2020). To avoid being rejected, many LGB older adults concealed their sexual orientation (D'Augelli et al., 2001), increasing the likelihood of experiencing social isolation and not benefitting from the LGB community connectedness. Indeed, LGB older individuals are more likely to live alone compared with heterosexual cisgender older adults (Kim \& Fredriksen-Goldsen, 2014). In this regard, Adams et al. (2003) highlighted the opportunities in online contexts for LGB older adults, who may feel free to express themselves, as well as to find romance and companionship, in dating websites specifically addressed to their age groups.

\section{Relationship Between Online Sexual Activities and Sexual Permissiveness}

In general, sexual attitudes and sexual behavior are linked (Albarracin et al., 2001; Cha et al., 2007). In particular, studies on OSAs have shown that those engaging in these activities are more likely to endorse sexually permissive attitudes (Braun-Courville \& Rojas, 2009). In addition, gender differences in sexual attitudes have been documented, with men being more permissive than women towards various sexual behaviors (Peplau, 2003), including both solitary and shared arousal-oriented sexual activities (Byers \& Shaughnessy, 2014). However, other findings have suggested that men and women are similar in their attitudes toward sex, as well as in other aspects of their sexual life (Petersen \& Hyde, 2010).

Within the research tradition on online sexuality, sexual permissiveness has represented a central topic over the past decades, primarily in youth studies, which have provided substantial evidence of the association between the use of pornography and sexual permissiveness (e.g., BraunCourville \& Rojas, 2009; Peter \& Valkenburg, 2008). In this regard, young viewers of pornography reported a more relaxed attitude toward premarital sexual relationships and a greater acceptance of casual sex (e.g., Braun-Courville \& Rojas, 2009; Peter \& Valkenburg, 2010). Furthermore, adolescents visiting sexually explicit web sites are more likely to engage in high-risk sexual behaviors such as having multiple partners, practicing anal sex, and using substances during sex (Braun-Courville \& Rojas, 2009).

This research tradition has attracted great attention to and raised debate and concerns about the potential influence of exposure to online sexually explicit content on psychosocial and sexuality development in adolescence (Davis, 2012). However, the notion that the use of pornography could increase the sexual permissiveness of adolescents has recently been challenged by a Croatian longitudinal study (Martyniuk \& Štulhofer, 2018), which has revealed among adolescents no significant pathways leading from the use of sexually explicit material to sexual permissiveness.

In addition, sexual permissiveness has been examined in relation to any participation in online dating. In a cross-sectional study on the sociodemographic and psychosocial correlates of using Tinder, the widespread geosocial networking application, in a sample of young adults, Shapiro et al. (2017) found that being less sexually permissive was associated with a lower likelihood of using the application. Findings from a recent literature review on the topic (Bonilla-Zorita et al., 2020) have indicated that sexual permissiveness is one of the personality characteristics presenting a positive correlation with online dating and sex-searching in this context (Peter \& Valkenburg, 2007; Sumter \& Vandenbosch, 2019). In this regard, a recent Italian study investigating the use of different sources of information about sexuality in a sample of 193 university students (Fino et al., 2020) found that the self-reported use of the Internet for this purpose was a predictor of liberal attitudes in relation to the students' own sexual behaviors, including autoeroticism, different heterosexual practices, homosexuality, sexual variations, and commercial sex, after controlling for age, gender, sexual orientation, and religious beliefs; on the other hand, no significant relations with the participants' attitude toward others' sexual behaviors was found.

As regards the older generations of web users, relationships between sexual attitudes and OSAs have not been examined to date. Generally, older people seem to be less permissive than their younger counterparts in their attitudes toward sexuality (Le Gall et al., 2002; Waite et al., 2009), although later cohorts of older adults seem to report more positive and liberal attitudes toward sexuality, giving more prominence to their own sexuality (Schmidt \& Matthiesen, 2003; Syme, 2014; Træen \& Villar, 2020). Furthermore, older people with more permissive attitudes showed a greater knowledge about sexuality and more frequent sexual activity in later life (De Lamater, 2012; Even-Zohar \& Werner, 2019). However, little is known about this topic in older ages, and an investigation into the role of sexual permissiveness in OSAs is needed. 


\section{Sexual Activity, Health, and the Needs of Italian Older Adults}

Italy is the country with the highest percentage of older people in Europe, second only to Japan in the world (Population Reference Bureau, 2020). By 2050, people aged 65 or older will constitute more than one third of the whole Italian population and, according to the National Institute of Statistics, the average life expectancy will be 85 years for women and 81 for men (Duretto \& Pinna, 2019). Furthermore, as in other industrialized countries, also in Italy the last thirty years have seen a huge improvement in the quality of life of older people, leading to a growing scientific interest in sexuality in later life as an integral part of the physical and mental health of each aging individual (Borella \& De Beni, 2015; Rossi et al., 2001). Nevertheless, there is a scarcity of research on OSAs in Italian older people.

A study conducted about 20 years ago, examining sexual activity and interest in an Italian sample of 335 people aged between 65 and 106 years, revealed that roughly one-third of the participants were still sexually active, whereas twothirds were still interested in sex, suggesting that sexual interest remains, regardless of sexual activity (Dello Buono et al., 1998). The most important variables relevant to maintaining sexual activity proved to be being male, married, younger, cognitively unimpaired, self-sufficient, satisfied with one's present life, and having a higher educational level. As regards gender differences, in relation to both sexual interest and activity, the absence of arthrosis and the maintenance of good social-relational functions were predictive factors for men, whereas the absence of depression and anxiety was predictive for women (Dello Buono et al., 1998). A more recent survey from the Social Investment Studies Center conducted in 2007 found that, among 1298 Italian older people, about $73.4 \%$ aged $61-70$ years old and $39.1 \%$ of people over 70 were still sexually active (Borella \& De Beni, 2015). However, Umidi et al. (2007), investigating the sexual and affective sphere in 230 older residents in Northern Italy, highlighted how the persistence of desire and the demand for physical contact varied as a function of the social context and the cultural conditioning, with differences revealed between city dwellers and those in provincial towns. In addition, most people expressed a desire for greater attention on this topic.

Despite the scarcity of empirical studies on sexuality in Italian older adults, there is an increasing awareness about this topic (Duretto \& Pinna, 2019). Sexual health and sexuality have increasingly been considered in the assessment of older adults' quality of life. Indeed, older people have begun to be included in sexuality education programs and sexual health promotion campaigns. Similarly, the need for training initiatives for health care providers is gaining substantial acknowledgement (e.g., Rossi et al., 2001).

Moreover, in recent years, the attention concentrated on Italian LGBT older adults has been rising (Scandurra et al., 2017). The existing findings have revealed the great invisibility of this population, due to a tendency of such individuals to conceal their own sexual identity. On the one hand, this concealment may be due to a lack of recognition of one's own sexual identity (Pietrantoni et al., 2000); on the other, it may be induced by the need for healthcare assistance (Rosati et al., 2020a, b). In fact, the heterosexism within health care environments may force LGBT individuals to return to the "closet" in later life or to avoid clinical settings, because of the fear of facing discrimination in a context which has historically stigmatized their identity group. Hence, specific training programs are needed for healthcare professionals and service providers, who may unknowingly neglect or discriminate against this group's needs, perpetuating stigma with an adverse impact on health (Rosati et al., 2020a, b).

\section{The Current Study}

The current study was aimed to investigate Internet usage for sexual-related purposes in a sample of Italian people aged over 50 years. Specifically, we were interested in exploring the prevalence and frequency with which Italian older adults engage in a range of OSAs, as well as the relationships between gender, sexual orientation, and sexual permissiveness with OSAs. Given the exploratory nature of this study, we adopted 50 years and over as a cut-off age for older adults. Although the cut-off age for the older individuals is conventionally 65 years, there is no general agreement on the age at which a person becomes old and the definition of "older person" varies from country to country (Kowal \& Dowd, 2001; Orimo et al., 2006; Rosati et al., 2020a, b). Indeed, studies focused on Internet use in older adults differ in their definition of chronological age (Hunsaker \& Hargittai, 2018), with some studies lowering the age floor of the older adult group to around 50 years old (e.g., Cotten et al., 2014; Ramón-Jerónimo et al., 2013; Ševcíková et al., 2020).

Based on previous studies (Döring \& Mohseni, 2019; Döring et al., 2015; Even-Zohar \& Werner, 2019; Shaughnessy et al., 2011; Træen et al., 2018), we hypothesized that (a) gender would be associated with online sexual arousal activities, with male participants being more likely to use S-OSA, P-OSA, and N-OSA than their female counterparts (hypothesis 1); (b) sexual orientation would be associated with all types of OSAs, with non-heterosexual participants being more likely to use S-OSA, P-OSA, and N-OSA than their heterosexual counterparts (hypothesis 2); and (c) sexual permissiveness would be associated with all types of 
OSAs, with participants with higher levels of sexual permissiveness being more likely to use S-OSA, P-OSA, and N-OSA than those with lower levels (hypothesis 3).

Finally, as sexual permissiveness seems to interact with both sexual orientation and gender (Peplau, 2003; Byers \& Shaughnessy, 2014), we hypothesized that it would moderate the effect of gender and sexual orientation on OSAs.

\section{Method}

\section{Procedures and Participants}

This study used a cross-sectional online survey. The survey was distributed through online social networks (e.g., Facebook), posting the invitation to take part in the study on Italian groups for people over 50. Additionally, as we were interested in exploring the role of sexual orientation in OSAs practiced by older adults, Italian LGBT associations were contacted and encouraged to disseminate the survey through their online networks and mailing lists. Thus, a snowball sampling recruitment procedure was implemented.

Participation was voluntary and no rewards were provided. After clicking on the link of the survey, the participants were directed to a page containing the informed consent and information about the researchers (affiliations, e-mails, and phone numbers of the principal investigator) and anonymity of the survey. The participants were informed about the objectives, potential risks and benefits of the survey, and their right to withdraw at any moment. At the end of the first page, the participants had to give their consent to take part in the survey by clicking on the button "I agree to participate in the survey."

The study was approved by the Ethical Committee of the University of Naples Federico II (project identification code: 6/2019; date of approval: 15 March 2019), as well as designed in accordance with the EU General Data Protection Regulation and the principles of the Declaration of Helsinki in relation to the Ethical Principles for Medical Research Involving Human Subjects. Privacy was guaranteed through the use of a secure gateway accessible only to the principal investigator. Furthermore, before sharing the dataset with other scholars, the principal investigator deleted the IP addresses of all the participants.

The participants were recruited between September 2019 and January 2020. The inclusion criteria to participate in the online survey were (1) being at least 50 years old, (2) having been resident in Italy for at least 30 years, and (3) having used the Internet for at least 5 years.

Data from 114 participants ( 85 men and 29 women) aged from 52 to 79 years old $(M=62.57 S D=6.19)$ were analyzed in this study. All the participants were cisgender (i.e., their gender identity was aligned with their biological sex).
As regards sexual orientation, 54 (47.4\%) self-identified as heterosexual, whereas 46 (52.6\%) as non-heterosexuals (i.e., lesbian, gay, or bisexual). Regarding ethnicity, most of the sample self-identified as Caucasians $(n=110 ; 96.5 \%), 1.8 \%$ $(n=2)$ as Hispanics/Latinos, and $1.7 \%(n=2)$ as "other." As regards educational level, $38 \%(n=43)$ of the sample had a high school diploma, whereas $31 \%(n=35)$ had a bachelor's degree. Finally, $61 \%(n=69)$ of the participants were in a stable relationship, and 33\% reported being currently religious (all these religious participants declared themselves to be Catholic).

\section{Measures}

Socio-demographic Characteristics. The participants were asked to indicate their age, sex assigned at birth (male, female, or other with specification), gender (men, women, transmen, transwomen, or other with specification), sexual orientation (heterosexual, gay/lesbian, bisexual, or other with specification), ethnicity, educational level (high school or less vs. college or more), current relationship status (no vs. yes), and current religious status (no vs. yes). For the purposes of the current study, sexual orientation was coded as "heterosexual" (0) or "non-heterosexual" (1).

Online Sexual Activities. The individual's engagement in OSAs was assessed through the nine-item questionnaire developed by Shaughnessy et al. (2011), consisting of three subscales: (1) engagement in non-arousal activities (N-OSA; two items), (2) engagement in solitary-arousal activities (S-OSA; four items), and (3) engagement in partnered arousal activities (P-OSA; three items). N-OSAs are described as sexually related activities not focusing on sexually stimulating materials but rather involving educational and relational experiences (e.g., "seeking dating partners online"). S-OSAs are described as activities involving the one-way access to or production of sexually explicit stimuli (e.g., "viewing or posting sexually explicit pictures or videos"). P-OSAs are understood to be interactive, requiring the participation of at least one other individual (e.g., "exchanging instant messages about desired or fantasized sexual acts with another person"). For each item, the participants were asked to indicate how frequently they had had that specific experience in the previous month, with response options ranging from "never" to "more than once a day" on a 7-point Likert scale. The responses were averaged for each scale to create a composite subscale of the frequency with which participants had engaged in each type of OSA, with higher scores reflecting a higher frequency. The internal consistency of all three scales was adequate $(\alpha=0.67,0.84$, and 0.90 for N-OSA, S-OSA, and P-OSA, respectively).

Sexual Permissiveness. The Permissiveness subscale of the Brief Sexual Attitudes Scale (BSAS; Hendrick et al., 2006) was used to measure the degree of sexual 
permissiveness of the respondents towards sex. This subscale is constituted by ten items and assesses a person's attitudes towards casual, "game playing" styles of sex. The response options range from "strongly disagree" to "strongly agree" on a 5-point Likert scale. The mean score was computed as a measure of the individual sexual permissiveness, with higher scores reflecting a more permissive attitude towards sex. The internal consistency of the scale was adequate $(\alpha=0.86)$.

\section{Statistical Analyses}

All the statistical analyses were performed with SPSS 26, with the level of significance set at 0.05 . No missing data were present in the dataset.

Bivariate correlations between the main variables of the study were calculated using Pearson's correlation coefficient.

We performed three hierarchical linear regression analyses, based on the three dependent variables (i.e., N-OSA, S-OSA, and P-OSA). In all these models, we entered the socio-demographic characteristics (i.e., age, educational level, relationship status, and religion) in step 1 as covariates, gender and sexual orientation in step 2, and sexual permissiveness in step 3. As a final step of each hierarchical regression analysis, interaction terms between sexual permissiveness and gender, as well as between sexual permissiveness and sexual orientation, were added in order to test the moderating role of sexual permissiveness in the relationships between gender and sexual orientation and engagement in OSAs. Ethnicity was not included as a covariate on account of the low number of non-Caucasian participants.

\section{Results}

\section{Prevalence and Frequency of Engagement in Online Sexual Activities}

The inspection of the frequencies of engagement in OSAs during the previous month revealed that $38.6 \%(n=44)$ of the sample had engaged in N-OSAs at least two or three times. Furthermore, $58.1 \%(n=66)$ of the participants reported having engaged in S-OSAs at least two or three times, whereas $29.9 \%(n=34)$ had engaged in P-OSAs.

\section{Descriptive Statistics and Bivariate Correlations}

Means, standard deviations, and bivariate correlations among the main variables of the study are reported in Table 1.

Age was negatively associated with S-OSAs and P-OSAs. Being less educated was associated with a greater engagement with P-OSAs. Being not in a stable relationship was linked to a greater engagement with N-OSAs. Being religious was associated only with lower levels of sexual permissiveness. Gender was associated with sexual permissiveness, with men reporting higher levels than women. Sexual orientation was associated with sexual permissiveness, S-OSAs and P-OSAs with non-heterosexual individuals reporting higher levels than their heterosexual counterparts. Higher levels of sexual permissiveness were related to higher levels of all kinds of OSA, and vice versa. Finally, OSAs were positively associated with each other.

Table 1 Bivariate correlations between socio-demographic characteristics, gender, sexual orientation, sexual permissiveness, and online sexual activities

\begin{tabular}{|c|c|c|c|c|c|c|c|c|c|c|}
\hline & 1 & 2 & 3 & 4 & 5 & 6 & 7 & 8 & 9 & 10 \\
\hline 1. Age & 1 & & & & & & & & & \\
\hline 2. Educational level & .15 & 1 & & & & & & & & \\
\hline 3. Being in a stable relationship & -.15 & .12 & 1 & & & & & & & \\
\hline 4. Being religious & .07 & .06 & .08 & 1 & & & & & & \\
\hline 5. Gender (women) & -.10 & -.05 & -.15 & -.07 & 1 & & & & & \\
\hline 6. Sexual orientation (non-heterosexual) & $-.19^{*}$ & -.10 & -.08 & -.09 & $-.38 * * *$ & 1 & & & & \\
\hline 7. Sexual permissiveness & -.16 & -.08 & .04 & $-.26 * * *$ & $-.33 * * *$ & .15 & 1 & & & \\
\hline 8. N-OSAs & -.12 & -.15 & $-.23 *$ & -.07 & $-.25 * * *$ & $.35 * * *$ & $.27 * * *$ & 1 & & \\
\hline 9. S-OSAs & $-.22 *$ & -.14 & -.09 & -.04 & $-.27 * * *$ & $.30 * * *$ & $.40 * * *$ & $.63 * * *$ & 1 & \\
\hline 10. P-OSAs & $-.26 * *$ & $-.24 *$ & -.12 & .05 & -.08 & $.27 * * *$ & $.29 * * *$ & $.55^{* * * *}$ & $.63 * * *$ & 1 \\
\hline
\end{tabular}

$N$-OSAs non-arousal online sexual activities, S-OSAs solitary arousal online sexual activities, $P$-OSAs partnered arousal online sexual activities, $M$ mean, $S D$ standard deviation

$* p<.05, * * p<.01, * * * p<.001$ 


\section{Associations of Online Sexual Activities with Gender, Sexual Orientation, and Sexual Permissiveness}

The results from the hierarchical linear regression analyses are reported in Table 2.

With respect to N-OSAs, block 1 and block 2 were significant, with being not in a stable relationship and nonheterosexual significantly predicting an increase in N-OSA engagement. Sexual permissiveness (block 3 ) was not significantly associated with N-OSAs.

Regarding S-OSAs, all blocks except the first (i.e., the control variables) were significant. Gender and sexual orientation significantly predicted S-OSAs, with men and non-heterosexual participants showing higher levels of S-OSAs. In the last block, sexual permissiveness was a significant predictor of S-OSAs, but gender did not prove to be significant.

Finally, when examining P-OSAs, all blocks were significant except block 2 (including gender and sexual orientation). Overall, age was negatively associated with P-OSAs, whereas high sexual permissiveness was linked to increasing engagement with P-OSAs.

Contrary to our expectations, sexual permissiveness did not moderate either the relationship of gender with OSAs or that of sexual orientation with OSAs (all $p \mathrm{~s}>0.05$ ).

\section{Discussion}

The aim of the current study has been to explore Internet usage for sexual purposes in a sample of Italian people aged over 50 years, in order to expand our understanding of OSAs, a phenomenon which has been gaining growing importance worldwide over the last two decades (Barrada et al., 2019), and to acquire an awareness of different expressions of the older adult sexuality. To our knowledge, this is the first study investigating OSAs among Italian older adults, highlighting a topic which is largely unknown in this socio-cultural context and providing Italian geriatric specialists, psychologists, and researchers in general with an outline of the dissemination of these behaviors among different groups of people, as well as their association with gender, sexual orientation, and sexual permissiveness.

A first exploratory aim was to investigate the prevalence and frequency with which the participants had engaged in various OSAs during the previous month, in order to assess the extent to which the Internet is an ongoing part of Italian aging individuals' sexual lives. The results suggested that OSAs among older adults are quite widespread, especially S-OSAs (e.g., watching sexually explicit videos or reading erotic material), with $58.1 \%$ of the sample reporting having engaged in solitary-arousal activities at least 2 or 3 times during the previous month. This result is in line with previous studies indicating that watching pornography is the most ubiquitous OSA reported (Cooper et al., 2003; Wéry \& Billieux, 2016). As previously noted, sexual behaviors that require no interaction with others (e.g., the viewing of pornography) may be preferable because it is the most rapid option to satisfy sexual desire via the Internet (Ballester-Arnal et al., 2017). Instead, with regard to P-OSAs (e.g., engaging in online sexual conversations or webcam sex with at least one other person), a lower percentage of participants (29.9\%) proved to have engaged in such activities at least 2 or 3 times during the previous month. In line with previous studies (Döring \& Mohseni, 2019), this result shows that some older adults may use the Internet to share sexual texts, photos, and videos. With the growing spread of mobile phones among older adults (Seifert \& Schelling, 2015), it is likely that P-OSAs are becoming more common among this group, since this specific sexual expression mostly occurs through smartphone applications (Van Ouytsel et al., 2016). As regards N-OSAs (e.g., seeking information about sexuality or navigating on dating websites), $38.6 \%$ of participants proved to have engaged at least 2 or 3 times during the previous month. This result seems to confirm that some older adults may use the Internet as a source of information and guidance about their sexuality (Fileborn et al., 2016), but also to make social connections and to seek sexual and romantic relationships (Alterovitz \& Mendelsohn, 2013; Wion \& Loeb, 2015). As regards specifically the search for sexual-related information, the relatively low percentages compared with other studies (Döring \& Mohseni, 2019; Wéry \& Billieux, 2016) may be due to the fact that the current study, unlike the previous ones, focuses specifically on people aged over 50 years, rather than considering a wide age range and different age cohorts.

With regard to the correlates of OSAs, the negative relationship of age with S-OSAs and P-OSAs is in line with previous studies (Garcia et al., 2016; Træen et al., 2018; Wysocki \& Childers, 2011) which suggested that the use of the Internet for various sexual purposes would decrease with increasing age, reflecting the decline in sexual interest and activity across later life (Træen et al., 2016), as well as the generally lower levels of Internet usage in older age groups (Schreurs et al., 2017). However, this relationship was not revealed with regard to N-OSAs, in partial contrast with Træen et al. (2018), who found that the use of the Internet to find a relationship partner decreased with increasing age in men. The reason why we did not find the same association might be that, as N-OSAs involve educational and relational experiences (e.g., visiting sexual educational websites and chatting on dating websites), they are not strictly related to sexual arousal, but to other aspects, such as communication, 


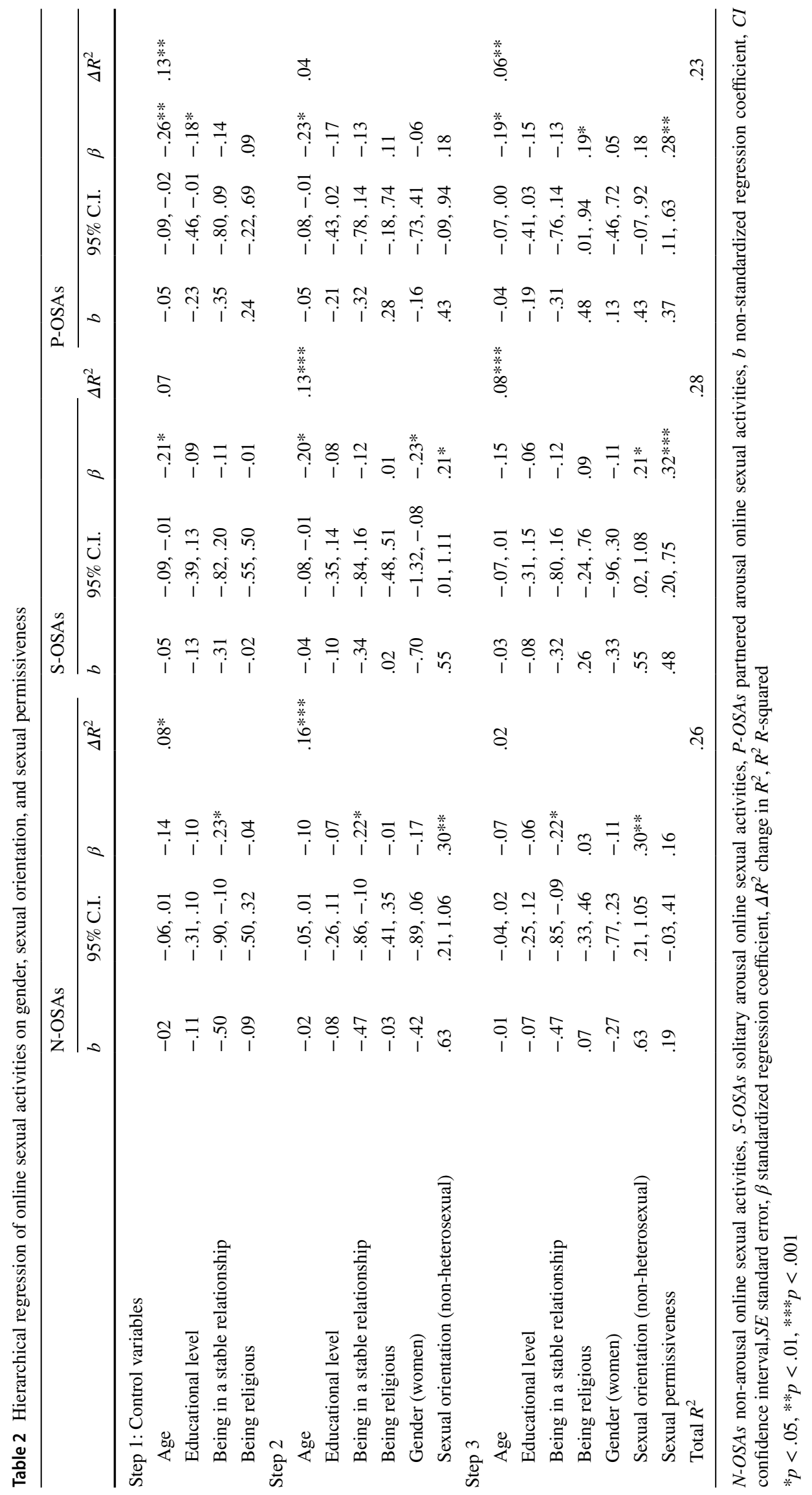


intimacy, affection, or empathy. All these dimensions are essential to sexuality in senescence (Gunzelmann et al., 2004) and therefore tend not to decline in later life, since their intensity does not depend on age but on other personal, social, and environmental factors (Hansson \& Carpenter, 1987). Moreover, the characteristics of accessibility, affordability, and anonymity (Cooper, 1998) make the use of the Internet particularly suitable for the educational and relational purposes sought by older adults, given the perceived barriers to talking about the topic of sexuality during faceto-face interactions in live contexts and the possible feelings of embarrassment and shame due to the internalization of prejudices on sexuality in old age (Hughes \& Lewinson, 2015; O'Brien et al., 2011). The role of the Internet as a potential means to fulfill the need for companionship and to find romantic relationships (Vandeweerd et al., 2016; Wion $\&$ Loeb, 2015) is confirmed by our findings which, in line with Træen et al. (2018), revealed a link between relationship status and N-OSAs, with higher levels of N-OSA engagement in participants who are not in a stable relationship. However, having or not a stable relationship is not significantly associated with P-OSAs engagement. This finding may be interpreted considering previous studies showing that having a partner would be highly predictive of continued sexual interest (e.g., De Lamater, 2012) and that older adults without a partner would ascribe less importance to sexual activity and its necessity for a good relationship (e.g., Rheaume \& Mitty, 2008). Hence, the scarce sexual interest of non-partnered people could explain why not being in a relationship is not linked to a greater engagement in OSAs involving other persons. Finally, no association was found between OSAs and religious status, although the latter was associated with lower levels of sexual permissiveness, confirming previous studies (e.g., Le Gall et al., 2002).

In support of our first hypothesis, findings revealed that gender was significantly associated with S-OSAs, with men being more likely to engage in such activities. This result is in line with previous findings (Döring \& Mohseni, 2019) suggesting that older men are more commonly involved in solo-sex activities, especially in terms of the use of pornography. As previously argued (Döring, 2009; Döring et al., 2015), this gender effect might be due to the higher frequency of masturbation in men than women, to the greater diffusion of male-oriented pornography, and to the more permissive attitude of men toward sexuality in general and sexually explicit materials (Petersen \& Hyde, 2010). However, our hypothesis is not confirmed in relation to P-OSAs and N-OSAs, since no significant associations with gender were found. In this regard, our results seem to be in line with those obtained by Döring et al. (2015), who argued that the use of sexually explicit Internet material is the only type of OSA showing a strong relationship with gender. Accordingly, this could mean that gender gaps are smaller in other OSA experiences, in line with the general decline of a gender gap in relation to sexual behavior (Petersen \& Hyde, 2010).

In support of our second hypothesis, the results showed a predictive role of sexual orientation in connection with S-OSAs and N-OSAs, as we found that being non-heterosexual was associated with an increase in engagement in such activities. These results are consistent with previous studies reporting higher levels of OSA engagement among LGB people (Shaughnessy et al., 2011; Ballester-Arnal et al., 2017; Giordano \& Cashwell, 2017), with the exception of P-OSAs. Thus, our study seems to confirm the crucial role of the Internet for LGB people who, even in older adulthood, find in the web a source of information about sexuality and sexual stimulation, as well as an avenue to seek romantic and sexual relationships. This may be particularly true in Italy, where heteronormativity is still pervasive, especially among older people (Baiocco et al., 2013; Lingiardi et al., 2015; Scandurra et al., 2020b). Indeed, the attitude of Italian people toward non-heterosexual orientations has historically been ambivalent. Non-heterosexual identities and behaviors have been viewed as morally reprehensible, deviating from a normal development, a sign of an artistic personality or a private matter which should not be spoken about (Baiocco et al., 2013; Capozzi \& Lingiardi, 2003). Despite the undoubted progress made in recent years (e.g., Lingiardi et al., 2015; Scandurra et al., 2019, 2020a, 2020b), Italy continues to show a limited support for LGBT individuals, who still experience high levels of oppression and victimization, a general delay in the recognition of their civil rights, and a lack of anti-discrimination legislation for their protection (Amodeo et al., 2018; Baiocco et al., 2013; Bochicchio et al., 2019; Lingiardi et al., 2015; Monaco, 2020; Scandurra et al., 2018). In this regard, many LGB older people who have spent their youth and early adulthood in Italy tend to conceal their sexual identity in offline contexts (Pietrantoni et al., 2000; Scandurra et al., 2017).

Despite being used as a coping strategy (Meyer, 2007), sexual identity concealment is a known source of psychological distress (Pachankis, 2007) and an internalized mechanism generally hard to deconstruct in later life (Cohler \& Hostetler, 2007; Rosenfeld, 2009). It may deprive LGB older people of social opportunities to meet romantic and sexual partners in their identity communities. The cyber-space provides an anonymous, reliable, and comfortable source of contacts and relationships and a safe context in which to express one's own marginalized identity (Mehra et al., 2004). In addition, LGB older people are at an elevated risk of physical health disparities (Fredriksen-Goldsen et al., 2013; Scandurra et al., 2017) which, in turn, may affect their sexual life (Lee et al., 2013, 2015). Relying on the Internet for information and guidance about one's own sexual health might be a crucial resource for LGB individuals, given the 
pervasive heteronormativity of health-care systems and the lack of adequate training for health-care personnel on LGB issues, which deny LGB individuals the sense of safety and freedom in which to talk about their sexuality and sexual life (Rosati et al., 2020a, b).

As regards our third hypothesis, we found that sexual permissiveness was significantly associated with OSAs, with the exception of N-OSAs. In general, this result can represent further evidence of the association between sexual attitudes and sexual behavior (Albarracin et al., 2001; Cha et al., 2007). Moreover, it is consistent with previous studies which have revealed higher levels of sexual activity in older people having more permissive attitudes (De Lamater, 2012; EvenZohar \& Werner, 2019). Thus, it is plausible to hypothesize that older people who have developed permissive sexual attitudes following the evolution of sexual habits in the Italian socio-cultural context are more likely to use new technologies to enhance the expression of their sexuality.

Furthermore, this finding revealed the role of users' beliefs, preferences, and expectations in the selection and use of media content in later life (Slater, 2015; Zillman \& Bryant, 1985) and particularly, in our case, in relation to online sexual material that can be found in pornographic and cybersex websites. This result may be interpreted in light of the selective exposure hypothesis, which postulates that media users select contents according to their individual personal background, which comprises attitudes, beliefs, needs, and desires (Zillman \& Bryant, 1985), including attitudes toward sexuality. However, in line with a recent study by Martyniuk and Štulhofer (2018) focused on adolescence, we may interpret our findings in light of the most recent theoretical frameworks on the relationship between media use and personal attitudes (i.e., reinforcing spirals model; Slater, 2015), which assume that: (1) users' choices of specific media content are shaped by their social context and individual characteristics and (2) there is a dynamic and mutual influence between users' choices of media content and the effect of the content on the users, which may impact their future use.

With respect to N-OSAs, our findings are in contrast with previous studies which found an association of sexual permissiveness with online dating (Bonilla-Zorita et al., 2020; Peter \& Valkenburg, 2007; Shapiro et al., 2017; Sumter \& Vandenbosch, 2019) and with the use of the Internet as a source of information about sexuality (Fino et al., 2020). Our results seem to suggest that sexual permissiveness in later life is associated only with arousal activities, either with a partner or alone, whereas this is not a relevant variable with regard to non-arousal activities, such as seeking information about sexuality or navigating on dating websites. Further studies might examine if and how personality, age, and cultural-specific variables may influence the dynamic of such relationships, taking into consideration the diversified activities included within the range of N-OSAs.

Finally, contrary to our expectations, our findings did not show any moderating effect of sexual permissiveness on the relationship of gender with OSAs. These results are congruent with an emerging perspective in literature on gender differences in sexuality which highlights that men and women are more similar in terms of sexual behaviors and attitudes than traditionally assumed (e.g., Petersen \& Hyde 2010). According to the gender similarity hypothesis (Hyde, 2005), men and women are more similar than different on most psychological variables. As for the sexual attitudes and behaviors, the gender gap reduction may be the result of an equal sexual socialization of men and women in Western cultures (Petersen \& Hyde, 2010). However, gender remains crucial within sexual research and additional studies including larger and more gender-balanced samples are needed to clarify and substantiate the results of this study.

\section{Limitations}

The current study has several limitations, which should be considered when interpreting the results. First, the small sample size and its specific composition do not allow any generalization of the results to the larger population of Italian older adults engaging in OSAs. Indeed, women were substantially outnumbered by men, most of the sample self-identified as Caucasians and all the participants were cisgender. Future studies should try to recruit a wider sample, diversified according to specific socio-demographic characteristics, such as gender and ethnicity. Moreover, due to the low number of participants, we could not explore the role of internal heterogeneity, assessing potential differences in relation to OSAs between lesbian women, gay men, and bisexual women and men. A more accurate approach addressing the differences within the LGB population is needed in future studies. In addition, we were not able to recruit people aged 80 and over, or older adults in institutional settings, who represent an important segment of the aging population.

Secondly, given the cross-sectional nature of the study, the directionality of the relationship between variables (gender, sexual orientation, sexual permissiveness, and OSAs) cannot be determined, since the inverse relationships are not excludable. Future studies using a longitudinal design may facilitate a greater understanding of the analyzed variables. Other biases potentially affecting the results should be considered. Despite the anonymity granted by the online questionnaire, older people may be particularly reluctant to admit their OSA involvement (Döring \& Mohseni, 2019). As previously argued by Træen et al. (2018), we can hypothesize that people with more permissive and liberal attitudes about sexuality were 
more likely to participate in this study compared with more traditional individuals. If so, this bias could have resulted in overestimates of the OSA engagement rates.

Finally, the OSA scale used in the current study (Shaughnessy et al., 2011) does not entirely represent all the sexual activities available online, since it does not consider all smartphone apps and other digital devices which are rapidly extending and improving Internet accessibility. To achieve this objective, after launching our survey, Bélanger Lejars et al. (2020) developed a new OSA scale which includes the breadth of activities currently available through personal digital device use.

\section{Conclusions}

In the current study, OSAs and their correlates (i.e., gender, sexual orientation, and sexual permissiveness) have been explored in a group of Italian older people, in order to expand our understanding of digital media as a way of expressing sexuality in later life. Our findings have highlighted that OSAs represent a relatively common experience among Italian older adults, offering them a means to explore and enrich their sexual life.

Our study highlights the necessity of including online resources in sexual health educational programs addressed at older people, as well as in training programs addressed at healthcare professionals and social workers working with this population, as healthcare systems are called upon to respond to life-span care needs (Freda et al., 2019; Scandurra et al., 2018b). Indeed, practitioners should be prepared to discuss with their older clients the use of the Internet as a normal, helpful, and engaging source of sexual health information, as well as a practical context of sexual expression and an accessible environment to find sexual and romantic partners. Furthermore, they should be able to provide their clients with advice and guidance for safe web surfing, helping them to identify reliable websites. Moreover, they should also be aware of the significant role that OSAs may play for LGB older people. Education and training on OSAs may help practitioners not only to individuate the older adults' sexual needs, but also to deconstruct ageist stereotypes and attitudes that are perpetuated within healthcare services. Indeed, raising awareness on different expressions of sexuality in older age may reduce invisibility of older adults' sexual life as well as the ageism.

Since the population of web surfers is aging and future generations of older adults will be regular Internet users, it is imperative to gain knowledge about the online sexual behavior and needs of such groups, whose attitudes are increasingly more liberal toward sexuality. However, considerable research is needed to examine accurately the characteristics of older individuals engaging in various types of OSA, to understand the impact of such activities on sexual well-being and quality of life, and to identify which types of services and information are necessary for older people.

Finally, effective advocacy strategies at all policy levels are needed to ensure that the sexuality of older adults becomes a high priority on the overall political agenda, with an acknowledgment of the role that the Internet has in its expression. The Internet expands the possibilities of older people to express their sexuality, but also presents several challenges that have not been well recognized. In addition to improving the accessibility of websites and web applications for older users, it is imperative to implement measures to protect their safety and privacy, in order to provide them safe online environments. The proposal of innovative practices, education programs, research, policies, and services should make it possible to enhance older adults' opportunities to exercise their sexual rights by taking full advantage of the resources of the Internet.

Author Contribution Conceptualization: Cristiano Scandurra, Fabrizio Mezza, Roberto Vitelli, Alain Giami, Paolo Valerio, and Anna Lisa Amodeo; methodology: Cristiano Scandurra, Fabrizio Mezza, Roberto Vitelli, Paolo Valerio, and Anna Lisa Amodeo; formal analysis and investigation: Cristiano Scandurra, Fabrizio Mezza, and Concetta Esposito; writing-original draft preparation: Cristiano Scandurra and Fabrizio Mezza; writing - review and editing: Concetta Esposito, Roberto Vitelli, Nelson Mauro Maldonato, Vincenzo Bochicchio, Alessandro Chiodi, Alain Giami, Paolo Valerio, and Anna Lisa Amodeo; resources: Roberto Vitelli, Nelson Mauro Maldonato, Vincenzo Bochicchio, Alessandro Chiodi, and Alain Giami; supervision: Alain Giami, Paolo Valerio, and Anna Lisa Amodeo. All authors read and approved the final manuscript.

Funding Open Access funding provided by Università degli Studi di Napoli Federico II.

\section{Declarations}

Conflict of Interest The authors declare that they have no conflict of interest.

Ethics Approval Approval was obtained from the Ethical Committee of Psychological Research of the University of Naples Federico II (project identification code: 6/2019; date of approval: 15 March 2019). The procedures used in this study adhere to the tenets of the Declaration of Helsinki.

Informed Consent Participants were informed about the objectives of the survey, completion times, benefits, and risks, as well as about the anonymity of the responses and the right to stop the survey in any point and for any reasons. Furthermore, participants were informed that the data collected would have been published in scientific journals in aggregate form. After reading all information, participants had to give their consent to participate in the online survey by clicking on the bottom "I agree to participate in the survey."

Open Access This article is licensed under a Creative Commons Attribution 4.0 International License, which permits use, sharing, adaptation, distribution and reproduction in any medium or format, as long as you give appropriate credit to the original author(s) and the source, provide a link to the Creative Commons licence, and indicate if changes 
were made. The images or other third party material in this article are included in the article's Creative Commons licence, unless indicated otherwise in a credit line to the material. If material is not included in the article's Creative Commons licence and your intended use is not permitted by statutory regulation or exceeds the permitted use, you will need to obtain permission directly from the copyright holder. To view a copy of this licence, visit http://creativecommons.org/licenses/by/4.0/.

\section{References}

Adams, M., Oye, J., \& Parker, T. (2003). Sexuality of older adults and the internet: From sex education to cybersex. Sexual and Relationship Therapy, 18(3), 405-415. https://doi.org/10.1080/14681 99031000153991.

Albarracin, D., Johnson, B. T., Fishbein, M., \& Muellerleile, P. A. (2001). Theories of reasoned action and planned behavior as models of condom use: A meta-analysis. Psychological Bulletin, 127(1), 142-161. https://doi.org/10.1037/0033-2909.127.1.142.

Alterovitz, S. S. R., \& Mendelsohn, G. A. (2013). Relationship goals of middle-aged, young-old, and old-old Internet daters: An analysis of online personal ads. Journal of Aging Studies, 27(2), 159-165. https://doi.org/10.1016/j.jaging.2012.12.006.

Amodeo, A. L., Esposito, C., Bochicchio, V., Valerio, P., Vitelli, R., Bacchini, D., \& Scandurra, C. (2018). Parenting desire and minority stress in lesbians and gay men: A mediation framework. International Journal of Environmental Research and Public Health, 15(10), 2318. https://doi.org/10.3390/ijerph15102318.

Baiocco, R., Nardelli, N., Pezzuti, L., \& Lingiardi, V. (2013). Attitudes of Italian heterosexual older adults towards lesbian and gay parents. Sexuality Research and Social Policy, 10(4), 285-292. https://doi. org/10.1007/s13178-013-0129-2.

Ballester-Arnal, R., Calvo, J. C., Gil-Llario, M. D., \& Gil- Julia, B. (2017). Cybersex addiction: A study on Spanish college students. Journal of Sex \& Marital Therapy, 43(6), 567-585. https://doi. org/10.1080/0092623X.2016.1208700.

Barrada, J. R., Ruiz-Gómez, P., Correa, A. B., \& Castro, Á. (2019). Not all online sexual activities are the same. Frontiers in Psychology, 10, 339. https://doi.org/10.3389/fpsyg.2019.00339.

Baumeister, R. F., Catanese, K. R., \& Vohs, K. D. (2001). Is there a gender difference in strength of sex drive? Theoretical views, conceptual distinctions, and a review of relevant evidence. Personality and Social Psychology Review, 5(3), 242-273. https://doi.org/10.1207/ s15327957pspr0503_5.

Bélanger Lejars, V. O., Bélanger, C. H., \& Razmak, J. (2020). Exploring new measures of online sexual activities, device use, and gender differences. Computers in Human Behavior, 108, 106300. https://doi.org/10.1016/j.chb.2020.106300.

Bochicchio, V., Perillo, P., Valenti, A., Chello, F., Amodeo, A. L., Valerio, P., \& Scandurra, C. (2019). Pre-service teachers' approaches to gender-nonconforming children in preschool and primary school: Clinical and educational implications. Journal of Gay and Lesbian Mental Health, 23(2), 117-144. https://doi. org/10.1080/19359705.2019.1565791.

Bonilla-Zorita, G., Griffiths, M. D., \& Kuss, D. J. (2020). Online dating and problematic use: A systematic review. International Journal of Mental Health and Addiction, Advance Online Publication. https://doi.org/10.1007/s11469-020-00318-9.

Borella, E., \& De Beni, R. (2015). Temi, problemi e prospettive della psicologia dell'invecchiamento e della longevità [Psychological themes, problems, and perspectives on aging and longevity]. In R. De Beni \& E. Borella (Eds.), Psicologia dell'Invecchiamento e della Longevità [Psychology of Aging and Longevity] (pp. 31-61). Bologna, IT: Il Mulino.
Bouman, W. P., Arcelus, J., \& Benbow, S. M. (2006). Nottingham study of sexuality \& aging (NoSSA I). Attitudes regarding sexuality and older people: A review of the literature. Sexual and Relationship Therapy, 21(2), 149-161. https://doi.org/10.1080/14681990600618879

Braun-Courville, D. K., \& Rojas, M. (2009). Exposure to sexually explicit web sites and adolescent sexual attitudes and behaviors. Journal of Adolescent Health, 45(2), 156-162. https://doi. org/10.1016/j.jadohealth.2008.12.004.

Byers, E. S., \& Shaughnessy, K. (2014). Attitudes toward online sexual activities. Cyberpsychology: Journal of Psychosocial Research on Cyberspace, 8(1), 10. https://doi.org/10.5817/cp2014-1-10

Capozzi, P., \& Lingiardi, V. (2003). Happy Italy? The Mediterranean experience of homosexuality, psychoanalysis and the mental health professions. Journal of Gay \& Lesbian Psychotherapy, 7(1/2), 93-116. https://doi.org/10.1300/J236v07n01 07.

Cha, E. S., Doswell, W. M., Kim, K. H., Charron-Prochownik, D., \& Patrick, T. E. (2007). Evaluating the theory of planned behavior to explain intention to engage in premarital sex amongst Korean college students: A questionnaire survey. International Journal of Nursing Studies, 44(7), 1147-1157. https://doi.org/10.1016/j. ijnurstu.2006.04.015.

Cohler, B. J., \& Hostetler, A. J. (2007). Gay lives in the third age: Possibilities and paradoxes. In P. Wink \& J. James (Eds.), The Crown of Life: Dynamics of the Early Post-Retirement Period (pp. 263-282). New York, NY: Springer.

Cooper, A. (1998). Sexuality and the Internet: Surfing into the new millennium. CyberPsychology \& Behavior, 1(2), 187-193. https://doi. org/10.1089/cpb.1998.1.187.

Cooper, A., Månsson, S. A., Daneback, K., Tikkanen, R., \& Ross, M. (2003). Predicting the future of Internet sex: Online sexual activities in Sweden. Sexual and Relationship Therapy, 18(3), 277-291. https://doi.org/10.1080/1468199031000153919.

Cotten, S. R., Ford, G., Ford, S., \& Hale, T. M. (2014). Internet use and depression among retired older adults in the United States: A longitudinal analysis. The Journals of Gerontology Series B: Psychological Sciences and Social Sciences, 69(5), 763-771. https://doi.org/10.1093/geronb/gbu018.

D’Augelli, A. R., Grossman, A. H., Hershberger, S. L., \& O'Connell, T. S. (2001). Aspects of mental health among older lesbian, gay, and bisexual adults. Aging \& Mental Health, 5(2), 149-158. https://doi. org/10.1080/13607860120038366.

Daneback, K., Cooper, A., \& Månsson, S. A. (2005). An Internet study of cybersex participants. Archives of Sexual Behavior, 34, 321328. https://doi.org/10.1007/s1s0508-005-3120-z.

Davis, V. (2012). Interconnected but underprotected? Parents' methods and motivations for information seeking on digital safety issues. Cyberpsychology, Behavior, and Social Networking, 15(12), 669-674. https://doi.org/10.1089/cyber.2012.0179.

De Lamater, J. D. (2012). Sexual expression in later life: A review and synthesis. Journal of Sex Research, 49(2), 125-141. https://doi. org/10.1080/00224499.2011.603168.

Dello Buono, M., Zaghi, P. C., Padoani, W., Scocco, P., Urciuoli, O., Pauro, P., \& De Leo, D. (1998). Sexual feelings and sexual life in an Italian sample of 335 elderly 65 to 106 -year-olds. Archives of Gerontology and Geriatrics, 26(1), 155-162. https://doi. org/10.1016/S0167-4943(98)80023-X.

Döring, N. M. (2009). The Internet's impact on sexuality: A critical review of 15years of research. Computers in Human Behavior, 25(5), 1089-1101. https://doi.org/10.1016/j.chb.2009.04.003.

Döring, N., Daneback, K., Shaughnessy, K., Grov, C., \& Byers, E. S. (2015). Online sexual activity experiences among college students: A four-country comparison. Archives of Sexual Behavior, 46(6), 1641-1652. https://doi.org/10.1007/s10508-015-0656-4. 
Döring, N., \& Mohseni, M. R. (2019). Are online sexual activities and sexting good for adults' sexual well-being? Results from a national online survey. International Journal of Sexual Health, 30(3), 250263. https://doi.org/10.1080/19317611.2018.1491921.

Duretto, V., \& Pinna, G. (2019). La sessualità nell'anziano [Sexuality in the elderly]. Italian Journal of Medicine, 7(4), 54-58.

Even-Zohar, A., \& Werner, S. (2019). Older adults and sexuality in Israel: Knowledge, attitudes, sexual activity and quality of life. Journal of Aging Science, 7, 209. https://doi.org/10.35248/2329-8847.19.7.209.

Fileborn, B., Lyons, A., Hinchliff, S., Brown, G., Heywood, W., \& Minichiello, V. (2016). Learning about sex in later life: Sources of education and older Australian adults. Sex Education, 17(2), 165-179. https://doi.org/10.1080/14681811.2016.1273829.

Fino, E., Pierleoni, L., Cosmi, V., Giuliani, M., \& Gambino, G. (2020). Using internet predicts attitudes towards sexual behaviour in Italian psychology students. Sexologies, 29(1), e27-e33. https://doi. org/10.1016/j.sexol.2019.10.001.

Freda, M. F., Savarese, L., Dolce, P., \& De Luca Picione, R. (2019). Caregivers' sensemaking of children's hereditary angioedema: A semiotic narrative analysis of the sense of grip on the disease. Frontiers in Psychology, 10, 2609. https://doi.org/10.3389/fpsyg .2019.02609.

Fredriksen-Goldsen, K. I., Kim, H.-J., Barkan, S. E., Muraco, A., \& Hoy-Ellis, C. P. (2013). Health disparities among lesbian, gay, and bisexual older adults: Results from a population-based study. American Journal of Public Health, 103(10), 1802-1809. https ://doi.org/10.2105/ajph.2012.301110.

Garcia, J. R., Gesselman, A. N., Siliman, S. A., Perry, B. L., Coe, K., \& Fisher, H. E. (2016). Sexting among singles in the USA: Prevalence of sending, receiving, and sharing sexual messages and images. Sexual Health, 13(5) 428-435. https://doi.org/10.1071/SH15240.

Gewirtz-Meydan A., Hafford-Letchfield T., Benyamini Y., Phelan A., Jackson J., Ayalon L. (2018). Ageism and sexuality. In L. Ayalon \& C. Tesch-Römer (Eds.), Contemporary Perspectives on Ageism. International Perspectives on Aging, vol 19 (pp. 149-162). Springer, Cham.

Giordano, A. L., \& Cashwell, C. S. (2017). Cybersex addiction among college students: A prevalence study. Sexual Addiction \& Compulsivity, 24(1/2), 47-57. https://doi.org/10.1080/10720 162.2017.1287612.

Gunzelmann, T., Rusch, B. D., \& Bräler, E. (2004). Attitudes towards eroticism and sexuality in the elderly over 60 years of age. Gesundheitswesen, 66(1), 15-20. https://doi. org/10.1055/s-2004-812704.

Haavio-Mannila, E., \& Kontula, O. (2003). Sexual trends in the Baltic Sea area. Helsinki, FIN: Population Research Institute.

Hansson, R., \& Carpenter, B. (1987). Relationship in old age. New York, NY: The Guildford Press.

Hässler, T., Ullrich, J., Bernardino, M., Shnabel, N., Laar, C. V., Valdenegro, D., \& Ugarte, L. M. (2020). A large-scale test of the link between intergroup contact and support for social change. Nature Human Behaviour, 4(4), 380-386. https://doi. org/10.1038/s41562-019-0815-z.

Hendrick, C., Hendrick, S. S., \& Reich, D. A. (2006). The brief sexual attitudes scale. Journal of Sex Research, 43(1), 76-86. https://doi.org/10.1080/00224490609552301.

Hughes, A. K., \& Lewinson, T. D. W. (2015). Facilitating communication about sexual health between aging women and their health care providers. Qualitative Health Research, 25(4), 540-550. https://doi.org/10.1177/1049732314551062.

Hunsaker, A., \& Hargittai, E. (2018). A review of Internet use among older adults. New Media \& Society, 20(10), 3937-3954. https:// doi.org/10.1177/1461444818787348.
Hyde, J. S. (2005). The gender similarities hypothesis. American Psychologist, 60(6), 581-592. https://doi.org/10.1037/0003-066x.60.6.581.

Kim, H.-J., \& Fredriksen-Goldsen, K. I. (2014). Living arrangement and loneliness among lesbian, gay, and bisexual older adults. The Gerontologist, 56(3), 548-558. https://doi.org/10.1093/geront/gnu083.

Klettke, B., Hallford, D. J., \& Mellor, D. J. (2014). Sexting prevalence and correlates: A systematic literature review. Clinical Psychology Review, 34(1), 44-53. https://doi.org/10.1016/j. cpr.2013.10.007.

Kowal, P., \& Dowd, J. E. (2001). Definition of an older person. Proposed working definition of an older person in Africa for the MDS Project. Geneva, CH: World Health Organization.

Le Gall, A., Mullet, E., \& Shafighi, S. R. (2002). Age, religious beliefs, and sexual attitudes. Journal of Sex Research, 39(3), 207-216. https://doi.org/10.1080/00224490209552143.

Lee, T. K., Breau, R. H., \& Eapen, L. (2013). Pilot study on quality of life and sexual function in men-who-have-sex-with-men treated for prostate cancer. The Journal of Sexual Medicine, 10(8), 2094-2100. https://doi.org/10.1111/jsm.12208.

Lee, T. K., Handy, A. B., Kwan, W., Oliffe, J. L., Brotto, L. A., Wassersug, R. J., \& Dowsett, G. W. (2015). Impact of prostate cancer treatment on the sexual quality of life for men-who-have-sex-with-men. The Journal of Sexual Medicine, 12(12), 2378-2386. https://doi. org/10.1111/jsm.13030.

Lewin, B., Fugl-Meyer, K., Helmius, G., Lalos, A., \& Månsson, S. A. (2000). Sex in Sweden: On the Swedish sexual life. Uppsala, SE: The National Institute of Public Health.

Lindau, S. T., \& Gavrilova, N. (2010). Sex, health, and years of sexually active life gained due to good health: Evidence from two US population based cross sectional surveys of ageing. British Medical Journal, 340, c810. https://doi.org/10.1136/bmj.c810.

Lindau, S. T., Schumm, L. P., Laumann, E. O., Levinson, W., O'Muircheartaigh, C. A., \& Waite, L. J. (2007). A study of sexuality and health among older adults in the United States. New England Journal of Medicine, 357(8), 762-774. https://doi. org/10.1056/NEJMoa067423.

Lingiardi, V., Nardelli, N., Ioverno, S., Falanga, S., Di Chiacchio, C., Tanzilli, A., \& Baiocco, R. (2015). Homonegativity in Italy: Cultural issues, personality characteristics, and demographic correlates with negative attitudes toward lesbians and gay men. Sexuality Research and Social Policy, 13(2), 95-108. https://doi. org/10.1007/s13178-015-0197-6.

Malta, S. (2007). Love actually! Older adults and their romantic internet relationships. Australian Journal of Emerging Technologies \& Society, 5(2), 84-102.

Mannheim, I., Schwartz, E., Xi, W., Buttigieg, S. C., McDonnellNaughton, M., Wouters, E. J. M., \& van Zaalen, Y. (2019). Inclusion of older adults in the research and design of digital technology. International Journal of Environmental Research and Public Health, 16(19), 3718. https://doi.org/10.3390/ijerph16193718.

Martyniuk, U., \& Štulhofer, A. (2018). A longitudinal exploration of the relationship between pornography use and sexual permissiveness in female and male adolescents. Journal of Adolescence, 69, 80-87. https://doi.org/10.1016/j.adolescence.2018.09.006.

Mazur, E., Signorella, M. L., \& Hough, M. (2012). Older adults and their Internet behaviors. In Z. Yan (Ed.), Encyclopedia of Cyber Behavior (pp. 608-619). Hershey, PA: IGI Global.

Mehra, B., Merkel, C., \& Bishop, A. P. (2004). The internet for empowerment of minority and marginalized users. New Media \& Society, 6(6), 781-802. https://doi.org/10.1177/146144804047513.

Meyer, I. H. (2007). Prejudice and discrimination as social stressors. In I. H. Meyer \& M. E. Northridge (Eds.), The Health of Sexual Minorities: Public Health Perspectives on Lesbian, Gay, 
Bisexual and Transgender Populations (pp. 242-267). New York, NY: Springer.

Minichiello, V., Rahman, S., Dune, T., Scott, J., \& Dowsett, G. (2013). E-health: Potential benefits and challenges in providing and accessing sexual health services. BMC Public Health, 13, 790. https://doi. org/10.1186/1471-2458-13-790.

Monaco, S. (2020). Being bisexual in contemporary Italy: Between stigma and desire of visibility. International Journal of Sociology and Social Policy, 9(20), 1-20. https://doi.org/10.1108/IJSSP -05-2020-0157.

Morelli, M., Chirumbolo, A., Bianchi, D., Baiocco, R., Cattelino, E., Laghi, F., \& Drouin, M. (2020). The role of HEXACO personality traits in different kinds of sexting: A cross-cultural study in 10 countries. Computers in Human Behavior, 113, 106502. https://doi. org/10.1016/j.chb.2020.106502.

O'Brien, R., Rose, P., Campbell, C., Weller, D., Neal, R. D., Wilkinson, C., \& Watson, E. (2011). "I wish I'd told them": A qualitative study examining the unmet psychosexual needs of prostate cancer patients during follow-up after treatment. Patient Education and Counseling, 84(2), 200-207. https://doi.org/10.1016/j.pec.2010.07.006.

Orimo, H., Ito, H., Suzuki, T., Araki, A., Hosoi, T., \& Sawabe, M. (2006). Reviewing the definition of "elderly." Geriatrics and Gerontology International, 6(3), 149-158. https://doi.org/10.111 1/j.1447-0594.2006.00341.x.

Pachankis, J. E. (2007). The psychological implications of concealing a stigma: A cognitive-affective-behavioral model. Psychological Bulletin, 133(2), 328-345. https://doi.org/10.1037/0033-2909.133.2.328.

Peplau, L. A. (2003). Human sexuality: How do men and women differ? Current Directions in Psychological Science, 12(2), 37-40. https ://doi.org/10.1111/1467-8721.01221.

Peter, J., \& Valkenburg, P. M. (2007). Who looks for casual dates on the internet? A test of the compensation and the recreation hypotheses. New Media \& Society, 9(3), 455-474. https://doi. org/10.1177/1461444807076975.

Peter, J., \& Valkenburg, P. M. (2008). Adolescents' exposure to sexually explicit internet material, sexual uncertainty, and attitudes toward uncommitted sexual exploration: Is there a link? Communication Research, 35(5), 579-601. https://doi. org/10.1177/0093650208321754.

Peter, J., \& Valkenburg, P. M. (2010). Processes underlying the effects of adolescents' use of sexually explicit Internet material: The role of perceived realism. Communication Research, 37(3), 375-399. https://doi.org/10.1177/0093650210362464.

Petersen, J. L., \& Hyde, J. S. (2010). A meta-analytic review of research on gender differences in sexuality, 1993-2007. Psychological Bulletin, 136(1), 21-38. https://doi.org/10.1037/a0017504.

Pietrantoni, L., Sommantico, M., \& Graglia, M. (2000). Anzianità impreviste. Una ricerca su omosessualità e terza età [Unexpected seniority. A research on homosexuality and the elderly]. Rivista del Servizio Sociale, 40(1), 31-42.

Population Reference Bureau (2020). Countries with the Oldest Populations in the World. Retrieved October 3, 2020, from https://www. prb.org/countries-with-the-oldest-populations/

Ramón-Jerónimo, M. A., Peral-Peral, B., \& Arenas-Gaitán, J. (2013). Elderly persons and internet use. Social Science Computer Review, 31(4), 389-403. https://doi.org/10.1177/0894439312473421.

Rheaume, C., \& Mitty, E. (2008). Sexuality and intimacy in older adults. Geriatric Nursing, 29(5), 342-349. https://doi.org/10.1016/j.gerin urse.2008.08.004.

Rosati, F., Pistella, J., \& Baiocco, R. (2020). Italian sexual minority older adults in healthcare services: Identities, discriminations, and competencies. Sexuality Research and Social Policy, Advance Online Publication. https://doi.org/10.1007/s13178-020-00443-z.

Rosati, F., Pistella, J., Nappa, M. R., \& Baiocco, R. (2020). The coming-out process in family, social, and religious contexts among young, middle, and older Italian LGBQ+ adults. Frontiers in Psychology, 11, 617217. https://doi.org/10.3389/fpsyg.2020.617217.

Rosenfeld, D. (2009). Heteronormativity and homonormativity as practical and moral resources: The case of lesbian and gay elders. Gender \& Society, 23(5), 617-638. https://doi. org/10.1177/0891243209341357.

Rossi, R., Simonelli, C., \& Dalia, E. (2001). La sessualità maschile nella terza età [Male sexuality in old age]. Giornale Italiano di Andrologia, 8(4), 156-164.

Scandurra, C., Bochicchio, V., Amodeo, A. L., Esposito, C., Valerio, P., \& Maldonato, N. M. (2018a). Internalized transphobia, resilience, and mental health: Applying the psychological mediation framework to Italian transgender individuals. International Journal of Environmental Research and Public Health, 15(3), E508. https://doi.org/10.3390/ ijerph15030508.

Scandurra, C., Mezza, F., Bochicchio, V., Valerio, P., \& Amodeo, A. L. (2017). La salute degli anziani LGBT dalla prospettiva del minority stress. Rassegna della letteratura e raccomandazioni di ricerca [LGBT elders health from the minority stress perspective. Literature review \& research recommendations]. Psicologia della Salute, 2, 70-96. https://doi.org/10.3280/PDS2017-002004.

Scandurra, C., Bochicchio, V., Dolce, P., Caravà, C., Vitelli, R., Testa, R. J., \& Balsam, K. F. (2020). The Italian validation of the gender minority stress and resilience measure. Psychology of Sexual Orientation and Gender Diversity, 7(2), 208-221. https://doi. org/10.1037/sgd0000366.

Scandurra, C., Monaco, S., \& Nothdurfter, U. (2020). Heteronormativity in Italy: Psychometric characteristics of the Italian version of the Heteronormative Attitudes and Beliefs Scale. Sexuality Research and Social Policy, Advance Online Publication. https ://doi.org/10.1007/s13178-020-00487-1.

Scandurra, C., Picariello, S., Scafaro, D., Bochicchio, V., Valerio, P., \& Amodeo, A. L. (2018b) Group psychodynamic counselling as a clinical training device to enhance metacognitive skills and agency in future clinical psychologists. Europe's Journal of Psychology, 14(2), 444-463.https://doi.org/10.5964/ejop.v14i2.1528

Scandurra, C., Vitelli, R., Maldonato, N. M., Valerio, P., \& Bochicchio, V. (2019). A qualitative study on minority stress subjectively experienced by transgender and gender nonconforming people in Italy. Sexologies, 28(3), e61-e71. https://doi.org/10.1016/j.sexol 2019.05.002.

Schmidt, G., \& Matthiesen, S. (2003). Spätmoderne 60-Jährige [Latemodern 60 years old]. In R. Forum (Ed.), Alter und Sexualität (Age and Sexuality) (pp. 16-24). Frankfurt, DE: BzgA FORUM.

Schreurs, K., Quan-Haase, A., \& Martin, K. (2017). Problematizing the digital literacy paradox in the context of older adults' ICT use: Aging, media discourse, and self-determination. Canadian Journal of Communication, 42(2), 359-377. https://doi.org/10.22230 /cjc. 2017v42n2a3130.

Seifert, A., \& Schelling, H. R. (2015). Mobile seniors: Mobile use of the Internet using smartphones or tablets by Swiss people over 65 years. Gerontechnology, 14(1), 57-62. https://doi.org/10.4017/ gt.2015.14.1.006.00

Ševčíková, A., Blinka, L., Škařupová, K., \& Vašek, D. (2020). Online sex addiction after 50: An exploratory study of age-related vulnerability. International Journal of Mental Health and Addiction, Advance Online Publication. https://doi.org/10.1007/s11469-01900200-3.

Shapiro, G. K., Tatar, O., Sutton, A., Fisher, W., Naz, A., Perez, S., \& Rosberger, Z. (2017). Correlates of tinder use and risky sexual behaviors in young adults. Cyberpsychology, Behavior, and Social Networking, 20(12), 727-734. https://doi.org/10.1089/ cyber.2017.0279.

Shaughnessy, K., Byers, E. S., \& Walsh, L. (2011). Online sexual activity experience in heterosexual students: Gender similarities and 
differences. Archives of Sexual Behavior, 40(2), 419-427. https ://doi.org/10.1007/s1s0508-010-96299-9.

Skałacka, K., \& Gerymski, R. (2018). Sexual activity and life satisfaction in older adults. Psychogeriatrics, 19(3), 195-201. https://doi.org/10.1111/ psyg. 12381.

Slater, M. D. (2015). Reinforcing spirals model: Conceptualizing the relationship between media content exposure and the development and maintenance of attitudes. Media Psychology, 18(3), 370-395. https ://doi.org/10.1080/15213269.2014.897236.

Sumter, S. R., \& Vandenbosch, L. (2019). Dating gone mobile: Demographic and personality-based correlates of using smartphone-based dating applications among emerging adults. New Media and Society, 21(3), 655-673. https://doi.org/10.1177/1461444818804773.

Syme, M. L. (2014). The evolving concept of older adult sexual behavior and its benefits. Generations: Journal of the American Society on Aging, 38(1), 35-41. https://doi.org/10.2307/26556024

Syme, M. L., \& Cohn, T. J. (2015). Examining aging sexual stigma attitudes among adults by gender, age, and generational status. Aging \& Mental Health, 20(1), 36-45. https://doi.org/10.1080/13607 863.2015.1012044.

Træen, B., Carvalheira, A. A., Kvalem, I. L., Hald, G. M. (2018). European older adults' use of the Internet and social networks for love and sex. Cyberpsychology: Journal of Psychosocial Research on Cyberspace, 12(3), article 1. https://doi.org/10.5817/CP2018-3-1.

Træen, B., \& Daneback, K. (2012). The use of pornography and sexual behaviour among Norwegian men and women of differing sexual orientation. Sexologies, 22(2), e41-e48. https://doi.org/10.1016/j. sexol.2012.03.002.

Træen, B., Hald, G. M., Graham, C. A., Enzlin, P., Janssen, E., Kvalem, I. L., \& Štulhofer, A. (2016). Sexuality in older adults (65+)—An overview of the literature, Part 1: Sexual function and its difficulties. International Journal of Sexual Health, 29(1), 1-10. https://doi. org/10.1080/19317611.2016.1224286.

Træen, B., \& Villar, F. (2020). Sexual well-being is part of aging well. European Journal of Ageing, 17(2), 135-138. https://doi. org/10.1007/s10433-020-00551-0.

Umidi, S., Pini, M., Ferretti, M., Vergani, C., \& Annoni, G. (2007). Affectivity and sexuality in the elderly: Often neglected aspects. Archives of Gerontology and Geriatrics, 44(1), 413-417. https:// doi.org/10.1016/j.archger.2007.01.058.
Vandeweerd, C., Myers, J., Coulter, M., Yalcin, A., \& Corvin, J. (2016). Positives and negatives of online dating according to women 50+. Journal of Women \& Aging, 28(3), 259-270. https://doi. org/10.1080/08952841.2015.1137435.

Van Ouytsel, J., Van Gool, E., Walrave, M., Ponnet, K., \& Peeters, E. (2016). Sexting: Adolescents' perceptions of the applications used for, motives for, and consequences of sexting. Journal of Youth Studies, 20(4), 446-470. https://doi.org/10.1080/13676 261.2016.1241865.

Waite, L. J., Laumann, E. O., Das, A., \& Schumm, L. P. (2009). Sexuality: Measures of partnerships, practices, attitudes, and problems in the national social life, health, and aging study. Journal of Gerontology: Social Sciences, 64(1), i56-i66. https://doi.org/10.1093/geron b/gbp038.

Wéry, A., \& Billieux, J. (2016). Online sexual activities: An exploratory study of problematic and non-problematic usage patterns in a sample of men. Computers in Human Behavior, 56, 257-266. https://doi. org/10.1016/j.chb.2015.11.046.

Wiederman, M. W. (2005). The gendered nature of sexual scripts. The Family Journal, 13(4), 496-502. https://doi.org/10.1177/10664 80705278729.

Wion, R. K., \& Loeb, S. J. (2015). Older adults engaging in online dating: What gerontological nurses should know. Journal of Gerontological Nursing, 41(10), 25-35. https://doi.org/10.3928/00989 134-20150826-67.

Wysocki, D. K., \& Childers, C. D. (2011). "Let my fingers do the talking": Sexting and infidelity in cyberspace. Sexuality \& Culture: An Interdisciplinary Quarterly, 15(3), 217-239. https://doi. org/10.1007/s12119-011-9091-4.

Zillman, D., \& Bryant, J. (1985). Selective exposure to communication. Mahwah, NJ: Erlbaum.

Publisher's Note Springer Nature remains neutral with regard to jurisdictional claims in published maps and institutional affiliations. 